\title{
Correlation between the Expression Levels of Circulating miR-21 and miR-192 and Clinicopathological Features in Plasma of Patients with Gastric Cancer in Iran
}

\author{
Fatemeh Asadi Rahmani ${ }^{1}$, Najmeh Ranji ${ }^{1,}{ }^{*}$, and Hamid Saeidi Saedi ${ }^{1,2}$ \\ 1 Department of Biology, Faculty of Sciences, Rasht Branch, Islamic Azad University, Rasht, Iran \\ ${ }^{2}$ Gastrointestinal and Liver Diseases Research Center, Guilan University of Medical Sciences, Rasht, Iran
}

* Corresponding author: Najmeh Ranji, Department of Biology, Faculty of Sciences, Rasht Branch, Islamic Azad University, Rasht, Iran. Tel: +981333424080. Email: n_ranji@iaurasht.ac.ir

Received 2021 March 02; Revised 2021 April 14; Accepted 2021 May 16.

\begin{abstract}
Background: Gastric cancer (GC) is the most prevalent malignancy worldwide and a common cause of death in Iran. Studies have proved that a variety of dysregulated microRNAs is involved in the development and progression of gastric cancer.

Objectives: The present study aimed to evaluate the expression levels of plasma circulating oncogenic miR-21 and miR-192 and their association with clinical phenotypes of patients with gastric cancer in the north of Iran.

Methods: Clinico-pathological analysis was conducted using a standard protocol and pathological tests. The expression levels of miR-21 and miR-192 were measured using quantitative reverse transcription-polymerase chain reaction in the plasma of twenty pre/postoperative gastric cancer patients and twenty healthy subjects. The receiver operating characteristic (ROC) curve of these microRNAs was analyzed to investigate their diagnosis properties.

Results: The study results indicated that plasma miR-21 expression was significantly associated with tumor stage and helicobacter pylori infection status ( $\mathrm{P}=0.024, \mathrm{P}=0.0004$, respectively). However, no association was observed between clinic-pathological characteristics and miR-192 expression. The results showed that the plasma levels of miR-21 $(\mathrm{P}=0.0001)$ and miR-192 $(\mathrm{P}=0.0007)$ were significantly higher in GC patients compared to those in healthy individuals. Furthermore, the ROC analyses yielded the mean \pm SD area under the curve (AUC) values of $0.9525 \pm 0.03(\mathrm{P}<0.0001)$ and $0.5925 \pm 0.09(\mathrm{P}=0.316)$ for miR-21 and miR-192, respectively. Pearson regression analysis showed that there was no significant correlation between the expression of miR-21 and miR-192 ( $\mathrm{P}=0.1507)$.

Conclusion: Based on the obtained results, the expression of the plasma level of miR-21 was significantly higher in gastric cancer patients compared to that in the healthy group. Furthermore, the higher levels of AUC in miR-21 indicated the potential role of miR-21 as a noninvasive biomarker for the prognosis of gastric cancer in the population of the north of Iran.
\end{abstract}

Keywords: Gastric cancer, miR-21, miR-192, Plasma, Receiver operating characteristic analysis

\section{Background}

Gastric cancer (GC) is the fourth most prevalent malignancy and the second leading cause of mortality worldwide (1). Based on the latest update of the International Agency for Research on Cancer (IARC), the incidence rates of the disease in different geographical regions are distinctly varied (2). Although the mortality rates and incidence of GC have decreased in the past 70 years in Iran (3) it still is the most common cancer in males and the second malignancy-related death among females (4). Based on the plethora of evidence in the literature multiple factors involved in the etiology of gastric malignancy include genetic alterations (mutations, epigenetic changes, and genetic polymorphism), infection such as Helicobacter pylori, lifestyle (diet), and metabolic risk factors (serum cholesterol) (1).

Molecular genetics studies proved that MicroRNAs (miRNAs) play diverse roles in the physiological and pathological state of GC $(5,6)$. miRNAs are a subset of non-coding RNAs with a length of $\sim 22$ nucleotides $(6,7)$ that are transcribed but not translated into proteins (8). It is believed that miRNAs have a unique ability to negatively regulate gene expression (9). Figure 1 presents a history of microRNAs biogenesis. Some microRNAs, such as miR-21 and miR-192 have oncogenic properties associated with various genetic pathways In GC $(9,10)$. Aberrant dysregulation of miRNAs has been observed in GC (5). Although different serum tumor markers, such as carcinoembryonic antigen and carbohydrate antigen 19-9 have been applied for the diagnosis of GC, these conventional tumor markers lack sufficient sensitivity and specificity to facilitate early detection of malignancies (11). Several studies have shown that some circulating miRNAs in GC patients were detectable in plasma. These miRNAs can be non-invasive blood-based biomarkers that were potentially used for the prognosis or diagnosis of GC patients in the future (11).

\section{Objectives}

The present study aimed to evaluate the correlation of clinicopathological features and the 


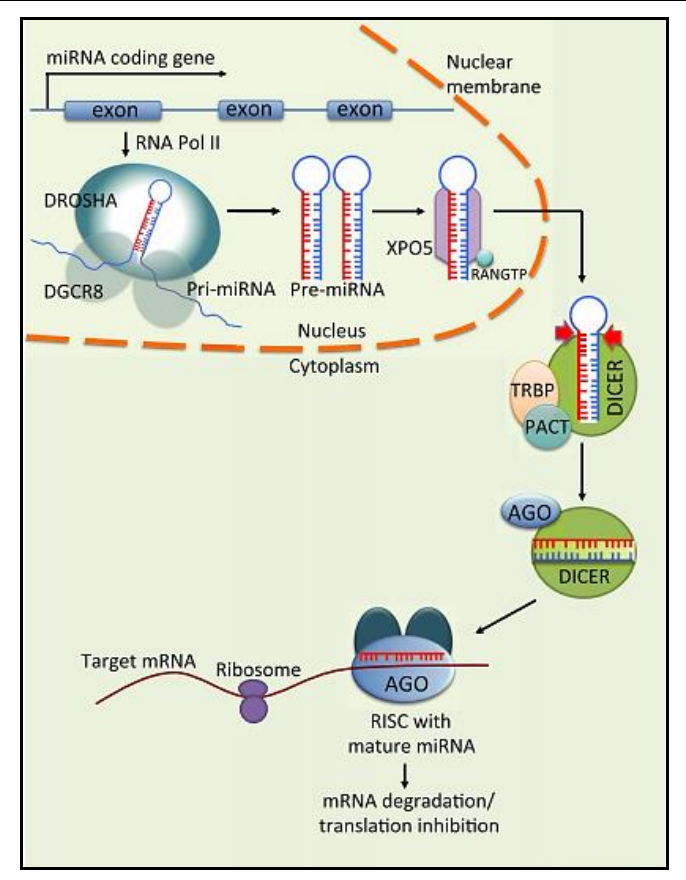

Figure 1. Biogenesis of microRNAs. They are produced by RNA polymerase II enzyme from nuclear DNA to generate primiRNAs. This molecule is processed to pre-miRNAs and it is then transferred to the cytoplasm by Exportin-5. In the cytoplasm, it is cleaved by RNase III enzyme Dicer to produce miRNA duplexes. Following pre-miRNAs, the guide strands are selected by AGO enzyme for integration into the RISC (the RNA induced silencing complex) complex. This is the last stage of miRNAs maturation process. Mature miRNAs binds complementary to the $3^{\prime} U T R$ of mRNAs resulting in denaturation or translational repression of target genes (12)

expression pattern of oncogenic miRNAs (miR-21, miR-192) in patients with GC in the north of Iran.

\section{Methods}

\subsection{Patients and samples}

The study protocol was approved by the Committee of Human Experiments of Rasht Branch, Islamic Azad University, Rasht, Iran (IR.IAU.RASHT.REC.1399.010), and informed consent was obtained from the participants at the beginning of the study. Plasma samples were obtained from 20 patients with pre/postoperative GC as well as 20 healthy volunteers (control group) in Jam laboratory and Razi Hospital (Rasht, Guilan province, Iran). The participants' demographic, clinical, and pathological data were collected which included gender, age, smoking status, tumor size, tumor location, tumor stage, helicobacter pylori infection status, and metastasis phenotype.

\subsection{RNA extraction and cDNA synthesis}

Total RNAs were extracted from plasma using a BON-miR RNA extraction kit (Stem Cell Technology Research Center, Tehran, Iran) according to the manufacturer's protocol. All plasma samples were transferred to free EDTA tubes and incubated in RT for 30 minutes. The samples were centrifuged at 3000rpm for 15 minutes in the RT. The cell pellets were then lysed using a lysis buffer. Afterward, the suspension was incubated with chloroform at $12000 \mathrm{rpm}$. Subsequently, cold isopropanol was added and incubated overnight at $-20^{\circ} \mathrm{C}$. The precipitated samples were washed with ethanol and the precipitated miRNAs were diluted by DEPC water following isopropanol elimination. The cDNA synthesis was performed using BON-miR

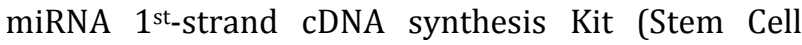
Technology Research Center, Tehran, Iran) according to the manufacturer's protocol. Activation of RNA Polyadenylation was performed using polyA polymerase at $37^{\circ} \mathrm{C}$ for $30 \mathrm{~min}$. Afterward, polyadenylated RNA was mixed with $1 \mu$ l of BON-RT adapter primer $(10 \mu \mathrm{M})$ and DEPC treated water and this mixture was incubated at $75^{\circ} \mathrm{C}$ for $5 \mathrm{~min}$ to remove secondary structures. Subsequently, RT enzyme, dNTP $(10 \mathrm{mM})$, and $5 \mathrm{X}$ buffer were added to the mixture. cDNA synthesis was carried out at $25^{\circ} \mathrm{C}$ for $10^{\circ} \mathrm{C}$ min, $42^{\circ} \mathrm{C}$ for $60 \mathrm{~min}$, and $70^{\circ} \mathrm{C}$ for $10 \mathrm{~min}$.

\section{3. $\mathrm{miR}-21$ and $\mathrm{miR}-192$ expression analysis by $Q-R T-P C R$}

Quantitative expression of miR-21 and miR-192 was carried out using the ABI StepOnePlusTM instrument. The primer pairs were purchased from the Stem Cell Technology Research Center (Tehran, Iran). Primers and chromosomal locations of microRNAs are presented in Table 1. The PCR reaction was carried out in the final volume of $13 \mu \mathrm{l}$ using BON-miR High specificity miRNA QPCR kit (Stem Cell Technology Research Center, Tehran, Iran) containing $6.3 \mu \mathrm{l}$ of $2 \mathrm{X}$ miRNA QPCR master mix (CYBR green), $1 \mu \mathrm{l}$ of cDNA, $0.5 \mu \mathrm{l}$ of each primer (forward and universal reverse primer), and $4.7 \mu \mathrm{l}$ of distilled water. The PCR amplification was performed in a 40 cycle based on the following program: $95^{\circ} \mathrm{C}$ for $5 \mathrm{~s}$ and $60^{\circ} \mathrm{C}$ for the $30 \mathrm{~s}$. The expression level of miR-21 and miR-192 was normalized by miR-93-5p (13). All reactions were performed at least in triplicate. Fold change of each microRNA was

\begin{tabular}{|c|c|c|c|c|}
\hline $\begin{array}{l}\text { MicroRNAs } \\
\text { Symbole }\end{array}$ & $\begin{array}{c}\text { Accession } \\
\text { Number(miRBase) }\end{array}$ & $\begin{array}{c}\text { Chromosome } \\
\text { location }\end{array}$ & Primers (5'to $\left.3^{\prime}\right)$ & $\begin{array}{c}\text { Anealing/Extension } \\
\text { tempreature }\left({ }^{\circ} \mathrm{C}\right)\end{array}$ \\
\hline miR-21 & MI0000077 & $\operatorname{ch} 17 q 23.2$ & $\begin{array}{c}\text { F.GCTTATCAGACTGATGTTG } \\
\text { R.GCGAGCACAGAATTAATACGACTC }\end{array}$ & 60 \\
\hline miR-192 & MI0000234 & $\operatorname{ch} 11 q 13.1$ & $\begin{array}{l}\text { F.TC TGA CTT ATG AAT TGA CAG C } \\
\text { R.GCGAGCACAGAATTAATACGACTC }\end{array}$ & 60 \\
\hline miR-93-5p & MI0000095 & ch 7q22.1 & $\begin{array}{c}\text { F.TAAAGTGCTGTTCGTGC } \\
\text { R.GCGAGCACAGAATTAATACGACTC }\end{array}$ & 60 \\
\hline
\end{tabular}


calculated by the equation $2^{-\Delta \Delta C t}$.

3.4. Receiver operating characteristic (ROC) curve analysis and microRNAs expression association

The ROC curve analysis was performed to evaluate the diagnostic value of miR-21and miR192expression levels in gastric tumor and control samples. Furthermore, a regression analysis was performed to obtain the probability correlation analysis of microRNAs expression in GC.

\subsection{Bioinformatics analysis of miRNAs-targets interactions}

In-silico analysis was carried out to examine the probability of the interaction of miRNAs-targets in GS pathways. miRNA sequences were obtained from the miRBase database (http://www.mirbase.org) and the interaction process was carried out using online RNA-Hybrid bioinformatics software (http://www. bibiserv.cebitec.uni-bielefeld.de). Interaction networks were built using Cytoscape software (version 3.7.1).

\subsection{Statistical Analysis}

Normality distribution of samples was tested using the Shapiro-Wilk test. The statistical analysis of miRNAs expression and clinic-pathology features in healthy individuals and those with GC was performed using the Mann-Whitney test. The ROC curve analysis was performed to evaluate the diagnostic value of miR-21 and miR-192 expression levels in the samples from plasma of GC patients using Prism software (version 8.0.2) based on RQ values. A Pvalue less than 0.05 was considered statistically significant.

\section{Results}

4.1. Clinico-pathological characteristics of the study participants

The participants in this study included twenty GC patients and twenty healthy individuals. The median age of participants was 65 years. It should be noted that $70 \%$ of patients $(n=20)$ were smokers and the rest were nonsmokers. Based on TMN classification, $85 \%$ and $15 \%$ of patients were in stage III and stage IV. Moreover, $80 \%$ of patients $(n=20)$ were positively in the metastasis stage. Analysis of tumor location revealed that both cardia and non-cardia GC were involved in the patient's pathogenicity. The cardia GC and non-cardia GC were diagnosed in $60 \%$ and $40 \%$ of patients, respectively. A brief history of clinical data is presented in Table 2 .

\begin{tabular}{|c|c|c|c|c|c|c|}
\hline \multirow[b]{2}{*}{$\begin{array}{l}\text { Demographical/ } \\
\text { Pathological data }\end{array}$} & \multicolumn{3}{|c|}{ miR-21 Expression } & \multicolumn{3}{|c|}{ miR-192 Expression } \\
\hline & $\begin{array}{l}<2 \text {-Fold } \\
(\mathrm{N}=20)\end{array}$ & $\begin{array}{l}\geq 2 \text {-Fold } \\
(\mathrm{N}=20)\end{array}$ & $P$-Value & $\begin{array}{l}<2 \text {-Fold } \\
(N=20)\end{array}$ & $\begin{array}{l}\geq 2 \text {-Fold } \\
(N=20)\end{array}$ & $P$-Value \\
\hline $\begin{array}{l}\text { Age (Year) } \\
\geq 65=8 \\
\leq 65=12\end{array}$ & $\begin{array}{l}3 \\
4\end{array}$ & $\begin{array}{l}5 \\
8\end{array}$ & 0.848 & $\begin{array}{l}6 \\
9\end{array}$ & $\begin{array}{l}2 \\
3\end{array}$ & 0.999 \\
\hline $\begin{array}{l}\text { Gender } \\
\text { Male }=12 \\
\text { Female }=8\end{array}$ & $\begin{array}{l}4 \\
4\end{array}$ & $\begin{array}{l}8 \\
4\end{array}$ & 0.456 & $\begin{array}{l}6 \\
3\end{array}$ & $\begin{array}{l}6 \\
5\end{array}$ & 0.58 \\
\hline $\begin{array}{l}\text { Smoking } \\
\text { Smokers }=14 \\
\text { Non=6 }\end{array}$ & $\begin{array}{l}6 \\
3\end{array}$ & $\begin{array}{l}8 \\
3\end{array}$ & 0.768 & $\begin{array}{l}8 \\
3\end{array}$ & $\begin{array}{l}6 \\
3\end{array}$ & 0.768 \\
\hline $\begin{array}{l}\text { Site of tumor } \\
\text { Upper Stomach (Cardia) }=12 \\
\text { Middle Stomach (Body)=5 } \\
\text { Whole Stomach(Antrum) }=3\end{array}$ & $\begin{array}{l}6 \\
3 \\
0\end{array}$ & $\begin{array}{l}6 \\
2 \\
3\end{array}$ & 0.219 & $\begin{array}{l}6 \\
2 \\
2\end{array}$ & $\begin{array}{l}6 \\
3 \\
1\end{array}$ & 0.76 \\
\hline $\begin{array}{l}\text { Tumor size } \\
<4 \mathrm{~cm}=12 \\
4-8 \mathrm{~cm}=8\end{array}$ & $\begin{array}{l}5 \\
2\end{array}$ & $\begin{array}{l}7 \\
6\end{array}$ & 0.443 & $\begin{array}{l}6 \\
4\end{array}$ & $\begin{array}{l}6 \\
4\end{array}$ & 0.99 \\
\hline $\begin{array}{l}\text { Tumor Stage } \\
\text { Stage III }=10 \\
\text { Stage IV }=10\end{array}$ & $\begin{array}{l}2 \\
7\end{array}$ & $\begin{array}{l}8 \\
3\end{array}$ & $0.024^{*}$ & $\begin{array}{l}2 \\
2\end{array}$ & $\begin{array}{l}8 \\
8\end{array}$ & 0.91 \\
\hline $\begin{array}{l}\text { Gross appearance } \\
\text { Superficial type }=10 \\
\text { Borrmann, I,II type }=8 \\
\text { Bormann III,IV type }=2\end{array}$ & $\begin{array}{l}4 \\
4 \\
1\end{array}$ & $\begin{array}{l}6 \\
4 \\
1\end{array}$ & 0.422 & $\begin{array}{l}5 \\
3 \\
1\end{array}$ & $\begin{array}{l}5 \\
5 \\
1\end{array}$ & 0.859 \\
\hline $\begin{array}{l}\text { Lymph node metastasis } \\
\text { Positive }=16 \\
\text { Negative }=4\end{array}$ & $\begin{array}{l}2 \\
2\end{array}$ & $\begin{array}{c}14 \\
2\end{array}$ & 0.093 & $\begin{array}{l}8 \\
2\end{array}$ & $\begin{array}{l}8 \\
2\end{array}$ & 0.99 \\
\hline $\begin{array}{l}\text { H. Pylori status } \\
\text { Infection=15 } \\
\text { Non-infection=5 }\end{array}$ & $\begin{array}{l}2 \\
5\end{array}$ & $\begin{array}{c}13 \\
0\end{array}$ & $0.0004^{*}$ & $\begin{array}{l}7 \\
2\end{array}$ & $\begin{array}{l}8 \\
3\end{array}$ & 0.79 \\
\hline
\end{tabular}

* Pathological significant changes presented as star 

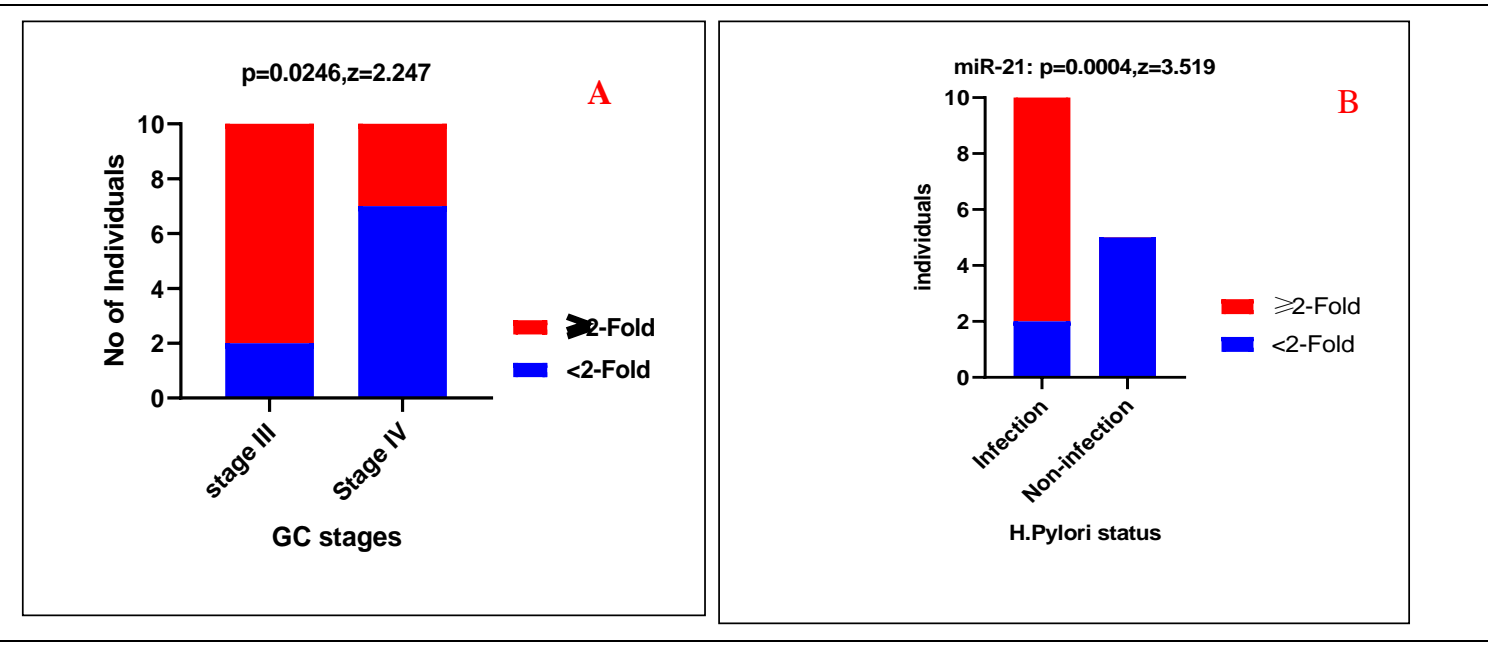

Figure 2. Correlation of Clinico-pathological features of GC patients and expression pattern of oncogenic miR-21 in plasma of GC patients. Data analysis revealed a significant association between A) tumor stages $(\mathrm{P}=0.0246)$ and $\mathrm{B})$ H.Pylori status $(\mathrm{P}=0.0004)$ with miR-21 expression in patients
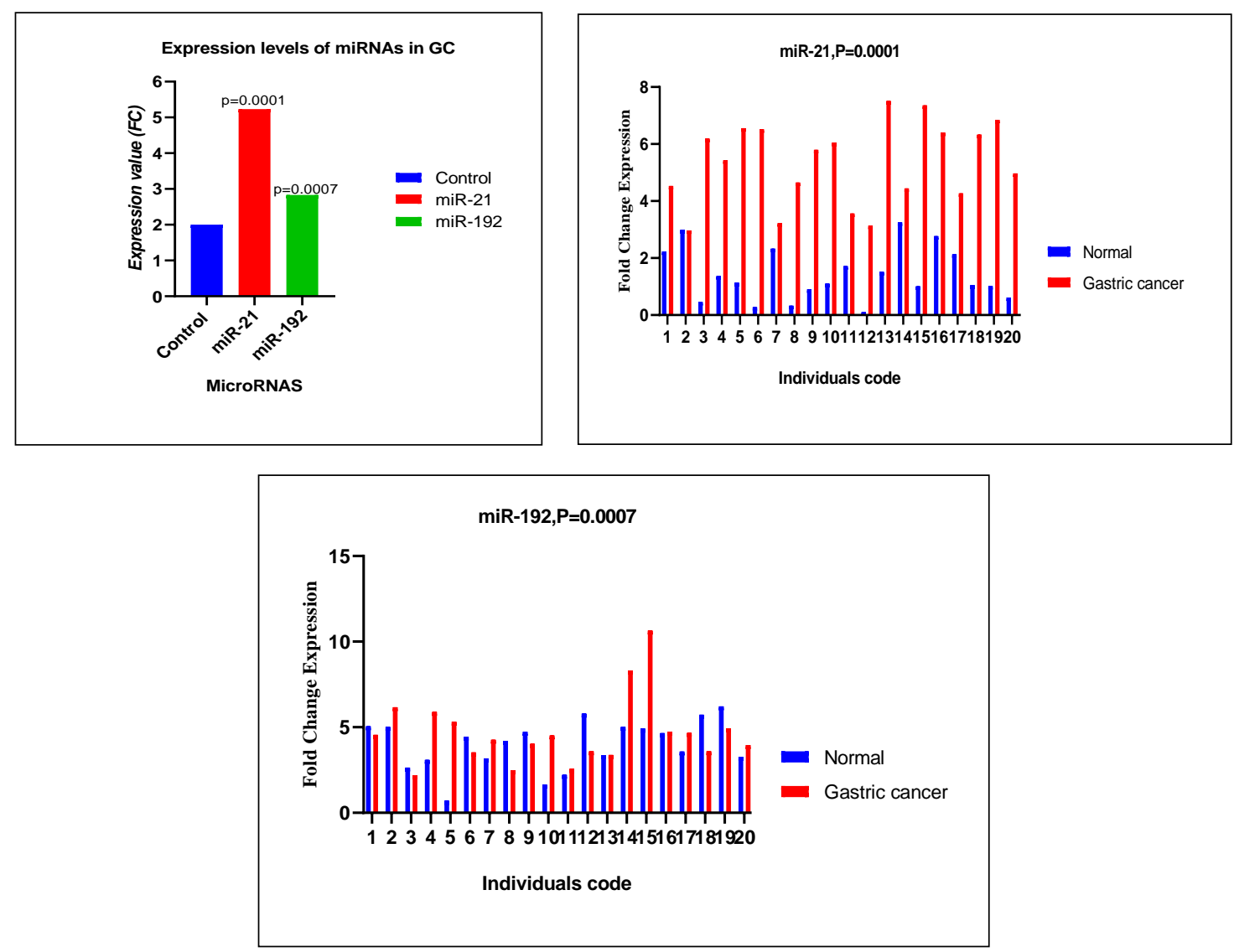

Figure 3. Relative expression of A) miR-21, B) miR-192 in patients and healthy individuals; and C) mean of their expression in two groups. miRNAs expression was normalized to miR-93-5p as endogenous internal control. The normalized expression value $(\mathrm{FC})$ was 2

\subsection{Quantitative expression of miR-21 and miR-192}

The study analysis showed significant overexpression of miR-21 and miR-192 oncogenes $(\mathrm{P}<0.0001$ and $\mathrm{P}=0.0007$, respectively) in plasma of
GC patients compared to that of the healthy individuals, with an average of 5.2 and 2.83-fold change, respectively (cut-off was set to 2 - fold). The results are presented in Figure 3 and Table 3. 
Table 3. miRNAs biological role, their targets in Gastric cancer and dysregulation of microRNAs involved in Iranian GC. The data presented in $\mathrm{CI}=95 \%$

\begin{tabular}{|c|c|c|c|c|c|c|c|}
\hline \multirow[b]{2}{*}{ Name } & \multirow{2}{*}{$\begin{array}{c}\text { Biological role in } \\
\text { GC }\end{array}$} & \multirow[b]{2}{*}{ mRNAs Targets } & \multirow{2}{*}{$\begin{array}{c}\text { Expression } \\
\text { Pattern in GC }\end{array}$} & \multirow[b]{2}{*}{ References } & \multicolumn{3}{|c|}{ Dysregulated pattern in GC-Patients } \\
\hline & & & & & Fold & $P$-Value & $\begin{array}{c}\text { CI } \\
95 \% \\
\end{array}$ \\
\hline $\operatorname{miR}-21$ & $\begin{array}{l}\text { Oncogenic(OncomiR, } \\
\text { Cell proliferation, } \\
\text { metastasis, } \\
\text { malignant } \\
\text { transformation, } \\
\text { invasion }\end{array}$ & $\begin{array}{c}\text { RECK,TIMP3,MMP2, } \\
\text { MMP9,SERPINI1, } \\
\text { TMP1,FASLG,BTG2, } \\
\text { PTEN,PDCD4,AKT, } \\
\text { NF-BK,EGR2,SMAD7 }\end{array}$ & Upregulated & $(13,14)$ & 5.2 & 0.0001 & $\begin{array}{c}1.223 \\
- \\
2.564\end{array}$ \\
\hline $\operatorname{miR}-192$ & $\begin{array}{l}\text { Oncogenic(OncomiR, } \\
\text { Cell proliferation, } \\
\text { invasion }\end{array}$ & ERCC1,ERCC2,BIM & Upregulated & $(15,16)$ & 2.83 & 0.0007 & $\begin{array}{c}1.102 \\
- \\
2.008\end{array}$ \\
\hline $\operatorname{miR}-93$ & Housekeeping gene & - & - & (13) & 2 & - & - \\
\hline
\end{tabular}
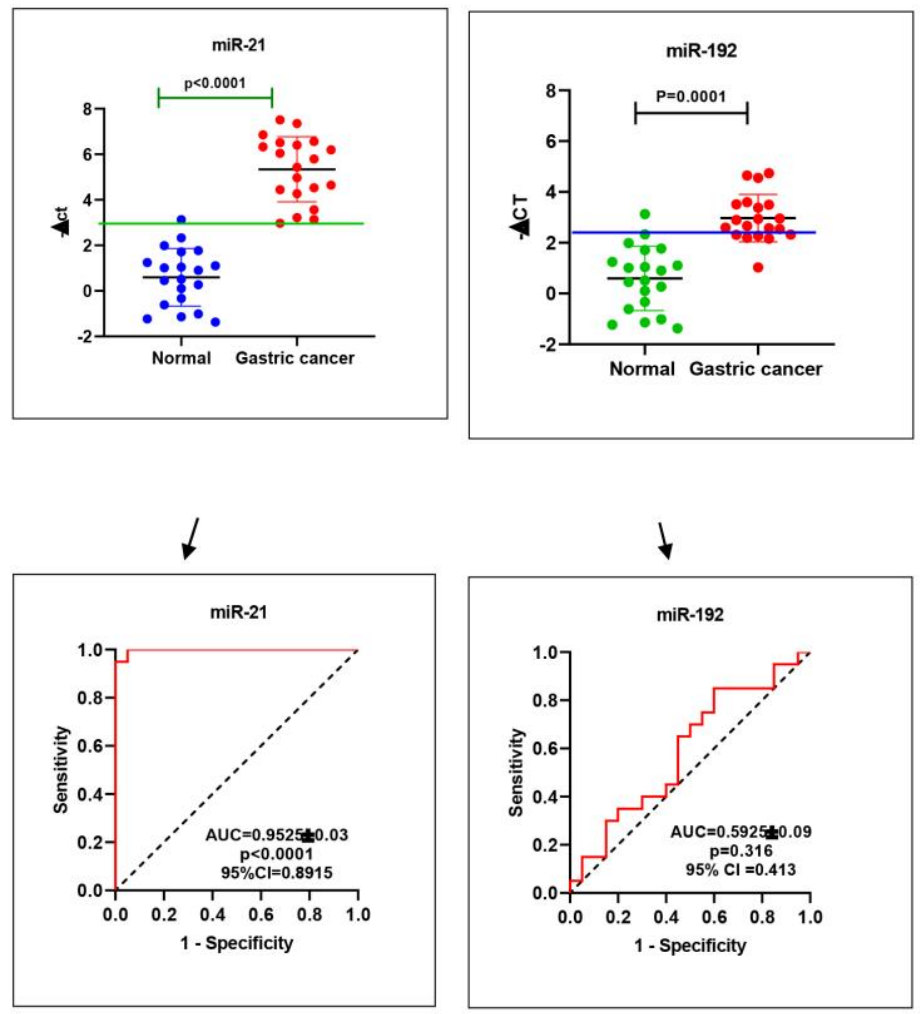

Figure 4. ROC curve analysis. The figure shows the comparison of two microRNAs and their
specific AUC based on their $\Delta \mathrm{Ct}$ distribution. miR- 21 with $0.95 \pm 0.03$ AUC (optimal cut off
value = Youden index= 3.1) compared with miR-192, AUC $=0.5925 \pm 0.09$ (optimal cutoff
value = Youden index $=2.1$ ) play as a potential biomarker for GC diagnosis patients in Iranian
population. The curve was analyzed using graph pad prism version 8.0.2

4.3. Correlation of clinicopathological feature and miRNAs expression

Histopathological data revealed a significant association between miR-21 expression in tumor stage $(\mathrm{P}=0.024)$ and $\mathrm{H}$. pylori status $(\mathrm{P}=0.0004)$ in gastric cancer patients (Figure 2). This clinicopathological association was not observed in miR-192 expression status. The analysis revealed that tumor stage $(\mathrm{P}=0.024)$ and $\mathrm{H}$. pylori infection status $(\mathrm{P}=0.0004)$ were statistically different in patients with overexpressed miR-21 $(\mathrm{F} \geq 2)$ compared to those with low miR-21 $(\mathrm{F}<2)$. However, there was no significant difference in other clinic-pathological features. In addition, no significant difference was observed in clinicopathological features with dysregulation of miR192 in plasma of GC patients ( $\mathrm{P}>0.05$, Table2).

\subsection{ROC curve analysis and miRNAs expression association evaluation}

Diagnostic evaluation of the ROC curve based on the distribution of $\Delta \mathrm{Ct}$ of miR-21 and miR-192 in GC patients revealed that the mean of area under the curve (AUC) for mir-21 and miR-192 was estimated at $0.9525 \pm 0.03 \quad(\mathrm{P}<0.0001,95 \% \quad \mathrm{CI}=0.89) \quad$ and 


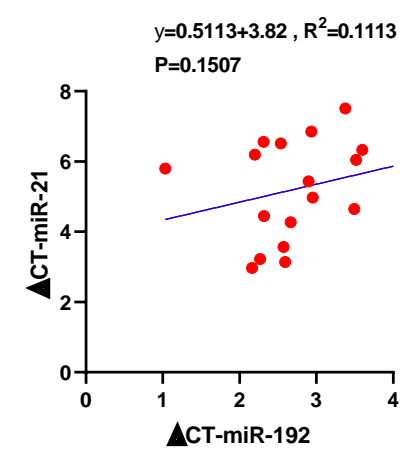

Figure 5. Pearson regression analysis of miR-21 and miR-192 expression based on $\Delta \mathrm{Ct}$ values. There was no significant correlation between the expression of two miRNAs $(P=0.1507)$

$0.5925 \pm 0.09(\mathrm{P}=0.316,95 \% \mathrm{CI}=0.41)$, respectively. The ROC analysis showed that miR-21 had the highest AUC value compared to miR-192, indicating that
miR-21 had a strong potential diagnosis value for GC detection in the Iranian population (Figure 4). Moreover, Pearson regression analysis (Figure 5) showed that there was no correlation between the expression levels of miR-21 and miR-192 $(\mathrm{y}=0.5113+3.83, \mathrm{R} 2=0.1113, \mathrm{P}=0.1507)$.

\subsection{In-silico analysis}

In-Silico pathway and gene enrichment analysis using Kyoto Encyclopedia of Genes and Genomes (KEGG) showed genetic interactions between miR-21, miR-192, and their genetic targets involved in GC. Data analysis revealed that these microRNAs regulate genes involved in the crucial signaling pathways, such as Apoptosis, AKT signaling pathway, tumorigenesis, and proliferation pathways. The potential target genes of these microRNAs were graphically presented as a network in Figure 6. The network was built using Cytoscape software (version 3.7.1). A genetic pathway of dysregulated microRNAs is presented in Figure 7.

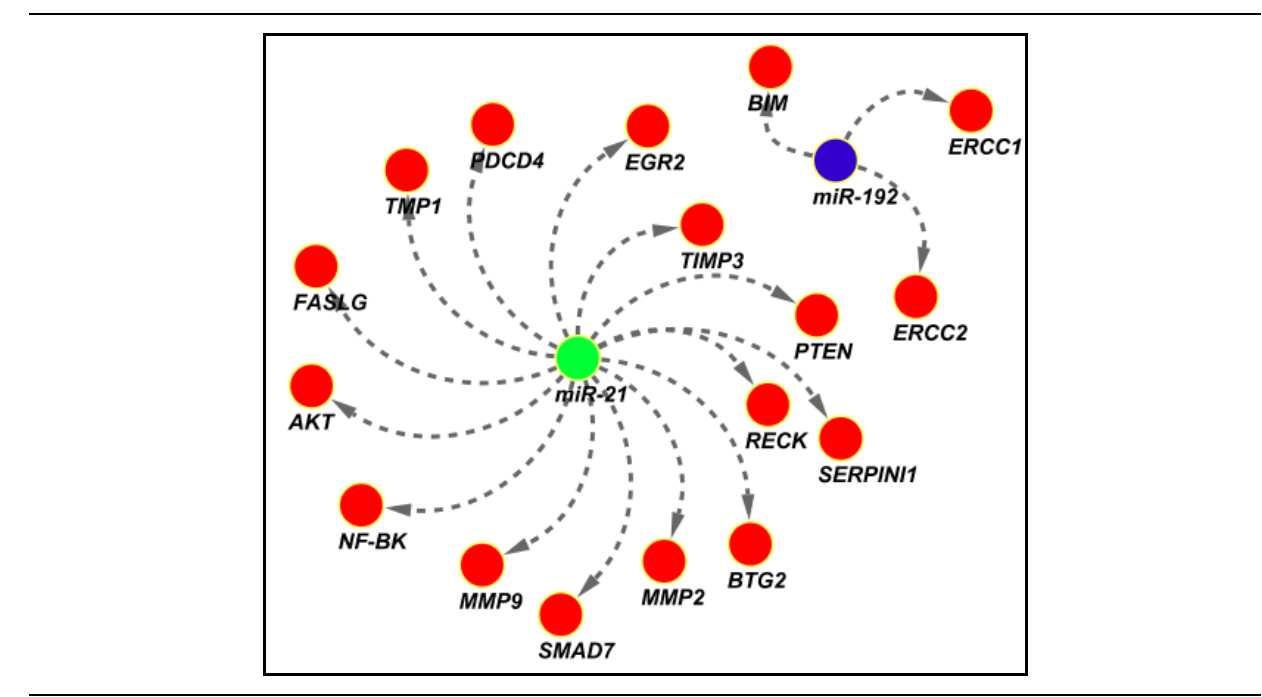

Figure 6. A Schematic network of In-silico-pathway analysis show the relationship between miRNAs and their target genes in Gastric cancer

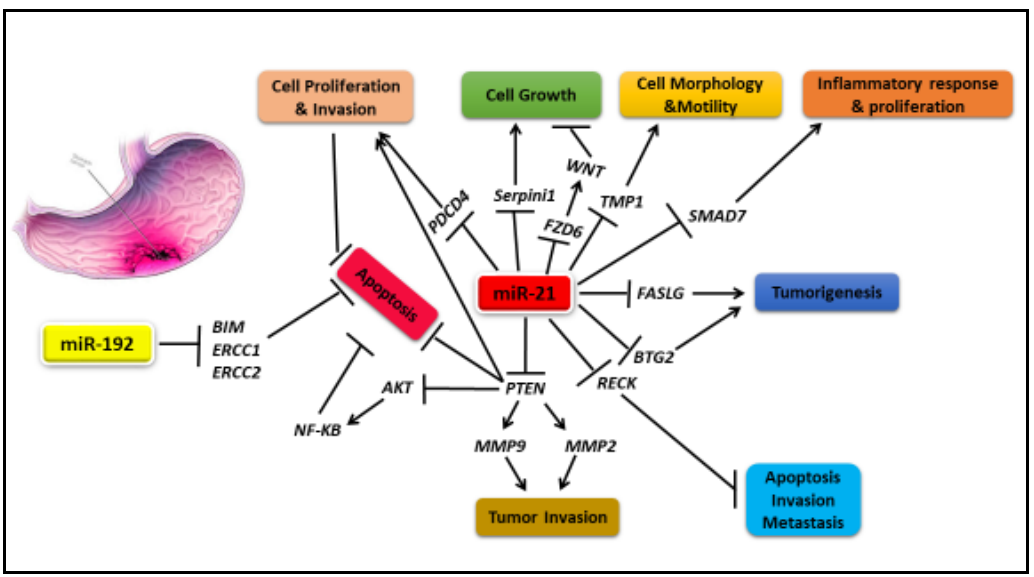

Figure 7. Genetics pathway of dysregulated miR-21, miR-192 and their genetics action in Gastric cancer. Pathway analysis show that miRNAs target different genes in various pathways that are crucial in tumor progression 


\section{Discussion}

Despite remarkable progress in the diagnosis and treatment of GC cases, the rate of mortality due to this cancer is still high. Many studies have demonstrated the dysregulation of miRNAs in gastric tumorigenesis and the fundamental role of these negative regulators in tumor progression $(5,10,13,17)$. Some miRNAs, such as miR-21 can in the future serve as a non-invasive biomarker for GC detection (18). The use of quantitative RT-PCR showed significant overexpression of miR-21 and miR-192 in 20 GC patients compared to controls.

Regarding clinicopathological characteristics, expression of plasma miR-21 was closely associated with tumor stages (III and IV; $\mathrm{P}=0.024$ ) and H.pylori infection status $(\mathrm{P}=0.0004)$. It has been reported that patients with positive serologic tests for $\mathrm{H}$. pylori have a higher risk of the development of GC (19). Previous study results revealed that tumor stages had a close association with GC tumorigenesis (20). In a study conducted by Wu et al., no correlation was found between miR-21 expression level and clinicopathological characteristics in the serum and peripheral blood mononuclear cell (PBMCs) of GC patients in 2010. Liu et al. reported that in 20 pairs of paraffin-embedded specimens of GC patients no correlation was observed between miR-21 and such factors as age, differentiation degree, histological type, lymph node metastasis, and H. pylori infection (21). The differences in miRNAs levels in normal and pathological conditions can be regarded as a promising biomarker for the diagnosis of GC patients. Based on the obtained results, circulating miR-21 can be introduced as a miR biomarker in stages III and IV of GC in cases with H. pylori infection in the north of Iran.

In the present study, ROC analysis showed a significant mean AUC of $0.95 \pm 0.03$ in miR-21 $(\mathrm{P}<0.0001)$ that can be used as a diagnostic marker for GC patients. These findings were in line with those obtained in other regions of Iran and other countries $(11,22,23)$. miR-21 is overexpressed in various cancers, such as breast cancer (24), lung cancer (25), colon cancer (26), and GC (20). Overexpression of miR-21 can change the biological process in the cell including proliferation (SMAD7, SERPINI1), apoptosis (RECK), invasion, (PTEN, RECK), and tumorigenesis (FASLG, BTG2) via regulating important target genes $(9,19)$.

There was no association between clinicopathological characteristics and expression of oncogenic miR-192 in the present study. The results of the study performed by $\mathrm{Xu}$ and Fan revealed that overexpression of miR-192 was related to the clinical features of GC, such as lymph node metastasis (27). Therefore, miR-192 can not be considered as a biomarker in GC patients in the study population.

A previous study showed that miR-192 has a dual function as oncomiR and tumor-suppressive miR in gastric GC. The results of the study conducted by Chiang et al. revealed that miR-192 was downregulated in GC patients compared to that in the individuals in the control group (16). However, Jin et al., showed that miR-192 has been significantly overexpressed in primary GC (28). Studies have shown that miR-192 inhibits the apoptosis process by targeting the main target genes including BIM, ERCC1, and ERCC2 in GC $(15,17,29)$. Although miR-192 has not previously been described as a predictive factor in GC, it has been detected in other malignancies as possible predictors (30). In a research study conducted by Odental et al., miR-192 was introduced as an indicator of a major histopathological response in esophageal cancer (31). However, based on the results of the present study, miR-192 was significantly overexpressed $(\mathrm{P}=0.0007)$ and the mean AUC analysis was not significant $(0.5925 \pm 0.09$, $\mathrm{P}=0.316$ ). Moreover, the miR-192 overexpression pattern was not associated with AUC; therefore, it cannot be considered as a prognostic biomarker in GC patients in the north of Iran.

\section{Conclusion}

Quantitative analysis showed significant overexpression of circulating miR-21 and circulating miR-192 $(\mathrm{P}<0.001)$ in the plasma of GC patients compared to healthy individuals. A significant correlation was observed between mir-21 expression and tumor stages III and IV and H. pylori. The higher levels of AUC in the circulating miR-21 indicated the potential role of circulating miR-21 as a noninvasive biomarker for the prognosis of GC in the north of Iran.

\section{Acknowledgments}

The authors would like to thank the employees and staff of Jam laboratory and Razi Hospital for their help and supports.

\section{Footnotes}

Conflicts of Interest: The authors declare that there is no conflict of interest regarding the publication of the present study.

Authors' Contribution: F. A. R. and N. R. contributed in the conceptualization and design of the article. F. A. R., N. R. and H. S. S. contributed analyzed and interpreted the data. F. A. R., and N. R. conducted the statistical analysis. F. A. R. and N. R. wrote and revised the manuscript. N. R. gave the final approval for this article. All authors are accountable for all aspects of the work.

Ethical Approval: The study protocol was approved by the Committee of Human Experiments of Rasht Branch, Islamic Azad University, Rasht, Iran (IR.IAU.RASHT.REC.1399.010). Informed consent was 
obtained from the participants at the beginning of the study.

Funding/ support: None

\section{References}

1. Ang TL, Fock KM. Clinical epidemiology of gastric cancer. Singapore Med J. 2014;55(12):621-8. doi: 10.11622/ smedj.2014174. [PubMed: 25630323].

2. Bray F, Ferlay J, Soerjomataram I, Siegel RL, Torre LA, Jemal A. Global cancer statistics 2018: GLOBOCAN estimates of incidence and mortality worldwide for 36 cancers in 185 countries. CA Cancer J Clin. 2018;68(6):394-424. doi: 10.3322/caac.21492. [PubMed: 30207593].

3. Almasi Z, Rafiemanesh H, Salehiniya H. Epidemiology characteristics and trends of incidence and morphology of stomach cancer in Iran. Asian Pac J Cancer Prev. 2015;16(7):2757-61. doi: 10.7314/apjcp.2015.16.7.2757. [PubMed: 25854359].

4. Farhood B, Geraily G, Alizadeh A. Incidence and mortality of various cancers in Iran and compare to other countries: a review article. Iran J Public Health. 2018;47(3):309-16. [PubMed: 29845017].

5. Ishiguro $H$, Kimura $M$, Takeyama $H$. Role of microRNAs in gastric cancer. World J Gastroenterol. 2014;20(19):5694-9. doi: 10.3748/wjg.v20.i19.5694. [PubMed: 24914330].

6. Pewarchuk ME, Barros-Filho MC, Minatel BC, Cohn DE, Guisier $\mathrm{F}$, Sage AP, et al. Upgrading the repertoire of miRNAs in gastric adenocarcinoma to provide a new resource for biomarker discovery. Int J Mol Sci. 2019;20(22):5697. doi: 10.3390/ijms20225697. [PubMed: 31739401].

7. Pakizehkar S, Ranji N, Naderi Sohi A, Sadeghizadeh M. Curcumin loaded PEG400-OA nanoparticles: A suitable system to increase apoptosis, decrease migration, and deregulate miR-125b/miR182 in MDA-MB-231 human breast cancer cells. Polymers Adv Technol. 2020;31(8):1793-804. doi: $10.1002 /$ pat.4906.

8. Macfarlane LA, Murphy PR. MicroRNA: Biogenesis, function and role in cancer. Curr Genomics. 2010;11(7):537-61. doi: 10.2174/138920210793175895. [PubMed: 21532838].

9. Ishimoto T, Baba H, Izumi D, Sugihara H, Kurashige J, Iwatsuki $\mathrm{M}$, et al. Current perspectives toward the identification of key players in gastric cancer micro RNA dysregulation. Int $J$ Cancer. 2016;138(6):1337-49. doi: 10.1002/ijc.29627. [PubMed: 26041092].

10. Wang J, Wang Q, Liu H, Hu B, Zhou W, Cheng Y. MicroRNA expression and its implication for the diagnosis and therapeutic strategies of gastric cancer. Cancer Lett. 2010; 297(2):137-43. doi: 10.1016/j.canlet.2010.07.018. [PubMed: 20797817].

11. Tsujiura M, Ichikawa D, Komatsu S, Shiozaki A, Takeshita H, Kosuga T, et al. Circulating microRNAs in plasma of patients with gastric cancers. Br J Cancer. 2010;102(7):1174-9. doi: 10.1038/sj.bjc.6605608. [PubMed: 20234369].

12. Shea A, Harish V, Afzal Z, Chijioke J, Kedir H, Dusmatova S, et al. MicroRNAs in glioblastoma multiforme pathogenesis and therapeutics. Cancer Med. 2016;5(8):1917 46. doi: doi.org/10.1002/cam4.775.[PubMed:27282910].

13. Song J, Bai Z, Han W, Zhang J, Meng H, Bi J, et al. Identification of suitable reference genes for qPCR analysis of serum microRNA in gastric cancer patients. Dig Dis Sci. 2012; 57(4):897-904. doi: 10.1007/s10620-011-1981-7. [PubMed: 22198701].

14. Karimi Kurdistani Z, Saberi S, Tsai KW, Mohammadi M. MicroRNA-21: mechanisms of oncogenesis and its application in diagnosis and prognosis of gastric cancer. Arch Iran Med. 2015;18(8):524-36. [PubMed: 26265521].

15. Xie X, Huang N, Zhang Y, Wei X, Gao M, Li M, et al. MiR-192-5p reverses cisplatin resistance by targeting ERCC3 and ERCC4 in SGC7901/DDP cells. J Cancer. 2019;10(4):1039-51. doi: 10.7150/jca.25814. [PubMed: 30854110].
16. Chiang Y, Zhou X, Wang Z, Song Y, Liu Z, Zhao F, et al. Expression levels of microRNA-192 and-215 in gastric carcinoma. Pathol Oncol Res. 2012;18(3):585-91. doi: 10.1007/s12253-011-9480-x. [PubMed: 22205577].

17. Lu J, Getz G, Miska EA, Alvarez-Saavedra E, Lamb J, Peck D, et al. MicroRNA expression profiles classify human cancers. Nature. 2005;435(7043):834-8.doi:10.1038/nature03702. [PubMed: 15944708].

18. Liu HS, Xiao HS. MicroRNAs as potential biomarkers for gastric cancer. World J Gastroenterol. 2014;20(34):12007-17. doi: 10.3748/wjg.v20.i34.12007. [PubMed: 25232237].

19. Sekar D, Krishnan R, Thirugnanasambantham K, Rajasekaran B, Islam VIH, Sekar P. Significance of microRNA 21 in gastric cancer. Clin Res Hepatol Gastroenterol. 2016;40(5):538-45. doi:10.1016/j.clinre.2016.02.010. [PubMed: 27179559].

20. Li BS, Zhao YL, Guo G, Li W, Zhu ED, Luo X, et al. Novel potential biomarkers for gastric cancer detection. PloS One. 2012;7(7):1-8. doi: 10.1371/journal.pone.0041629. [PubMed: 22860003].

21. Liu L, Chen Q, Lai R, Wu X, Wu X, Liu F, et al. Elevated expression of mature miR-21 and miR-155 in cancerous gastric tissues from Chinese patients with gastric cancer. $J$ Biomed Res. 2010;24(3):187-97. doi: 10.1016/S16748301(10)60028-0. [PubMed: 23554630].

22. Chan SH, Wu CW, Li AF, Chi CW, Lin WC. miR-21 microRNA expression in human gastric carcinomas and its clinical association. Anticancer Res. 2008;28(2A):907-11. [PubMed: 18507035].

23. Shiotani A, Murao T, Kimura Y, Matsumoto H, Kamada T, Kusunoki $\mathrm{H}$, et al. Identification of serum miRNAs as novel non-invasive biomarkers for detection of high risk for early gastric cancer. Br J Cancer. 2013;109(9):2323-30. doi: 10.1038/bjc.2013.596. [PubMed: 24104965].

24. Venturutti L, Romero LV, Urtreger AJ, Chervo MFa. Stat3 regulates ErbB-2 expression and co-opts ErbB-2 nuclear function to induce miR-21 expression, PDCD4 downregulation and breast cancer metastasis. Oncogene. 2016;35(17):220822. doi: 10.1038/onc.2015.281. [PubMed: 26212010].

25. Zhang J, Zhang C, Hu L, He Y, Shi Z, Tang S, et al. Abnormal expression of miR-21 and miR-95 in Cancer stem-like cells is associated with radioresistance of lung cancer. Cancer Invest. 2015;33(5):165-71. doi: 10.3109/07357907.2015.1019676. [PubMed: 25831148].

26. Tao YJ, Li YJ, Zheng W, Zhao JJ, Guo MM, Zhou Y, et al. Antisense oligonucleotides against microRNA-21 reduced the proliferation and migration of human colon carcinoma cells. Cancer Cell Int. 2015;15(1):1-10. doi: 10.1186/s12935-0150228-7. [PubMed: 26236156].

27. Wu J, Li G, Wang Z, Yao Y, Chen R, Pu X, et al. Circulating MicroRNA-21 is a potential diagnostic biomarker in gastric cancer. Dis Markers. 2015;2015:435656. doi: 10.1155/2015/ 435656. [PubMed: 26063956].

28. Jin Z, Selaru FM, Cheng Y, Kan T, Agarwal R, Mori Y, et al. MicroRNA-192 and-215 are upregulated in human gastric cancer in vivo and suppress ALCAM expression in vitro. Oncogene. 2011;30(13):1577-85. doi: 10.1038/onc.2010.534. [PubMed: 21119604].

29. Li S, Li F, Niu R, Zhang H, Cui A, An W, et al. Mir-192 suppresses apoptosis and promotes proliferation in esophageal aquamous cell caicinoma by targeting Bim. Int $J$ Clin Exp Pathol. 2015;8(7):8048-56. [PubMed: 26339371].

30. Sisic L, Vallbhmer D, Stoecklein NH, Blank S, Schmidt T, Driemel C, et al. Serum microRNA profiles as prognostic or predictive markers in the multimodality treatment of patients with gastric cancer. Oncol Lett. 2015;10(2):869-874. doi: 10.3892/ol.2015.3341. [PubMed: 26622585].

31. Odenthal M, Bollschweiler E, Grimminger PP, Schrder W, Brabender J, Drebber U, et al. MicroRNA profiling in locally advanced esophageal cancer indicates a high potential of miR192 in prediction of multimodality therapy response. Int J Cancer. 2013;133(10):2454-63. doi: 10.1002/ijc.28253. [PubMed: 23649428]. 